\title{
FORMAÇÃO INICIAL E CONTINUADA DE PROFESSORES QUE ENSINAM MATEMÁTICA: SOCIALIZANDO EXPERIÊNCIAS EXITOSAS DO DIEM
}

\author{
FORMATION OF TEACHERS WHO TEACH MATHEMATICS, TEACHING PRACTICE, SPECIFIC \\ DIDACTICS AND SOCIO-EDUCATIONAL DEVELOPMENT: SOCIALIZING SUCCESSFUL \\ EXPERIENCES
}

FORMACIÓN INICIAL Y CONTINUA DE PROFESORES QUE ENSEÑAN MATEMÁTICAS: SOCIALIZACIÓN DE EXPERIENCIAS EXITOSAS DEL DIEM

\author{
Geraldo Eustáquio \\ Moreira \\ (iD) 9 \\ Pós-Doutor em Educação \\ (ProPEd-UERJ) \\ Professor da Universidade de \\ Brasília (FE/UnB) \\ geust2007@gmail.com
}

\section{Lygianne Batista Vieira \\ iD 9}

Doutora em Educação (UnB)

Professora Substituta da

Universidade de Brasília (FE/UnB)

lygivieira@gmail.com

\section{Joeanne Neves Fraz (iD) 9}

Doutoranda em Educação na Universidade de Brasília (UnB)

fraz.joeanne@gmail.com

\section{Weberson Campos \\ Ferreira \\ (iD) 9}

Doutorando em Educação na

Universidade de Brasília

(PPGE/UnB)

webersoncamposprof@gmail.com

\section{Cristina de Jesus Teixeira iD 9}

Doutoranda em Educação na

Universidade de Brasília

(PPGE/UnB)

cristina.j.teixeira@gmail.com

\begin{abstract}
Resumo
Este texto tem como objetivo apresentar as ações desenvolvidas pelo grupo de pesquisa Dzeta Investigações em Educação Matemática - DIEM no âmbito de um projeto de pesquisa. Os participantes foram os membros do DIEM, estudantes de graduação (Licenciatura em Pedagogia) e pós-graduação da Universidade de Brasília - UnB e professores da Educação Básica de escolas públicas do Distrito Federal. A pesquisa integra-se, epistemologicamente, no âmbito da Educação Matemática e se alicerça em multimetodologias ativas de trocas de experiências e na construção coletiva de conhecimentos para o desenvolvimento de produtos e serviços, tendo como cerne a pesquisa colaborativa. Devido à complexidade e extensão do projeto, as ações foram desenvolvidas em diversas etapas e distintos instrumentos de recolha dos dados foram utilizados. Após a obtenção dos resultados, foram realizadas atividades que contribuíram para a elaboração de artigos, livros, capítulos de livros, dissertações, teses e comunicações científicas, bem como na produção de produtos e serviços educacionais e sociais.

Palavras-chave: Educação. Formação de Professores. Educação Matemática. Desenvolvimento Socioeducacional. Produtos Educacionais.
\end{abstract}

Recebido em: 3 de agosto de 2020.

Aprovado em: 10 de dezembro de 2020.

Como citar esse artigo (ABNT):

MOREIRA, Geraldo Eustáquio et al. Formação inicial e continuada de professores que ensinam matemática: socializando experiências exitosas do DIEM. Revista Prática Docente, v. 6, n. 1, e001, 2021. 


\section{Abstract}

This text aims to present the actions developed by the research group Dzeta Investigações em Educação Educação - DIEM as part of a research project. The participants were undergraduate students (Degree in Pedagogy) from the University of Brasília UnB and teachers of Basic Education in public schools in the Federal District. The research is integrated, epistemologically, within the scope of Mathematical Education and is based on active multimetodologies for the exchange of experiences and on the collective construction of knowledge for the development of products and services, with the core of collaborative research. Due to the complexity and extension of the project, the actions were developed in several stages and different instruments for data collection were used. After obtaining the results, activities were carried out that contributed to the preparation of articles, books, book chapters, dissertations, theses and scientific communications, as well as in the production of educational and social products and services.

Keywords: Education. Teacher Formation. Math Education. SocioEducational Development. Educational Products.

\section{Resumen}

Este texto tiene como objetivo presentar las acciones desarrolladas por el grupo de investigación Dzeta Investigações em Educação Educação - DIEM como parte de un proyecto de investigación. Los participantes fueron los miembros del DIEM, estudiantes de pregrado (Licenciatura em Pedagogia) y estudiantes de posgrado de la Universidad de Brasília - UnB y profesores de Educación Básica en escuelas públicas del Distrito Federal. La investigación se integra, epistemológicamente, en el ámbito de la Educación Matemática y se fundamenta en multimetodologías activas para el intercambio de experiencias y en la construcción colectiva del conocimiento para el desarrollo de productos y servicios, con el núcleo de la investigación colaborativa. Debido a la complejidad y extensión del proyecto, las acciones se desarrollaron en varias etapas y se utilizaron diferentes instrumentos para la recolección de datos. Luego de la obtención de los resultados, se realizaron actividades que contribuyeron a la elaboración de artículos, libros, capítulos de libros, disertaciones, tesis y comunicaciones científicas, así como en la producción de productos y servicios educativos y sociales.

Palabras clave: Educación. Formación de Profesores. Educación Matemática. Desarrollo Socioeducativo. Productos Educativos. 


\section{APRESENTAÇ̃̃o}

A construção de nossa identidade profissional surge a partir de marcas e trajetórias presentes na vida e nos percursos profissionais que estamos envolvidos, fortalecendo, assim, a maturidade científica e as produções que nos impulsionaram a pesquisar e pontuar os motivos que nos levaram a socializar as experiências exitosas provenientes do Grupo de Pesquisa "Dzeta Investigações em Educação Matemática - DIEM", alocado na Universidade de Brasília - UnB, especificamente na Faculdade de Educação - FE.

Nesse sentido, apresentamos algumas peças do quebra-cabeça que julgamos essenciais para a compreensão de nossa busca por uma identidade profissional de pesquisadores da Faculdade de Educação da Universidade de Brasília - FE/UnB, alinhados às diretrizes da formação de professores na perspectiva da Educação Matemática, da Educação Matemática Inclusiva e da Educação Matemática em Direitos Humanos, mais restritamente, vinculados aos eixos que abordam a formação de professores que ensinam Matemática.

As ações do projeto visam à construção do conhecimento e a melhoria da qualidade de vida no meio urbano e rural, por meio da edificação de investigações que atendam às demandas sociais e educacionais com vistas ao desenvolvimento de oficinas pedagógicas, aprendizagem em contextos diversos, elaboração de material instrucional e de tecnologia assistiva. Até o momento, tais ações possibilitaram o desenvolvimento de formas alternativas para a reorganização do trabalho pedagógico com base na proposição de ferramentas para o planejamento e gestão escolar, Educação Matemática para a promoção e defesa dos Direitos Humanos, proposição de problemas $^{1}$, ensino e aprendizagem da Matemática à distância, avaliação em larga escala e a produção de produtos educacionais.

Entendemos que nossa atuação como pesquisadores implica desassossego por outras conquistas e realizações. Nossas preocupações, para além do nosso universo profissional, fizeram-nos querer fortalecer nossas pesquisas no âmbito da Educação Matemática, impulsionando a divulgação dos resultados que alcançamos. É o momento de demonstrar e valorizar a maturidade científica do grupo como um todo!

Para além disso, o vislumbre que alcança a realização deste texto, propicia a legitimação de um movimento que fazemos há anos, tanto na Educação Básica quanto no Ensino Superior, principalmente porque a educação, de forma ampla, "é uma atividade essencialmente pluri e

\footnotetext{
${ }^{1}$ De acordo com Teixeira e Moreira (2020), a estratégia "proposição de problemas" se dá no sentido de ampliação da compreensão do desenvolvimento do trabalho pedagógico, englobando, para além da resolução de problemas, as estratégias de formulação e reformulação de problemas.
} 
interdisciplinar. Constitui um grande arco, onde há lugar para pesquisas e trabalhos dos mais diferentes tipos" (CARVALHO, 1994, p. 81), com sólidas bases na Educação, na Educação Matemática e nos processos de inclusão dos estudantes com necessidades educacionais específicas (NEE), que caracteriza-se como um campo de pesquisa amplo, que busca a melhoria do processo de ensino e aprendizagem (BICUDO, 1999; HYPOLITO, 2019).

Objetivamos, portanto, apresentar as ações desenvolvidas pelo grupo de pesquisa Dzeta Investigações em Educação Matemática - DIEM no âmbito de um projeto de pesquisa. Ao anunciar experiências referentes ao desenvolvimento de pesquisas sociais e educacionais empregadas na formação inicial e continuada de professores que, a partir da formação empreendida pelo grupo de pesquisa DIEM, os participantes puderam experimentar e desenvolver ações relacionadas ao processo de ensino e de aprendizagem de Matemática no âmbito do curso de Pedagogia da UnB, bem como em escolas públicas do Distrito Federal.

Desse modo, as experiências partiram de investigações dos diferentes conhecimentos adquiridos durante as reuniões do grupo de formação DIEM, suas articulações, aprendizagens e a influência desses conhecimentos sobre a atuação docente. Desenvolvemos ações de ensino, pesquisa e extensão voltados às populações interessadas nas questões relativas à educação e ao desenvolvimento social; promovemos atividades coligadas de pesquisadores, professores e estudantes de graduação e pós-graduação envolvidos nas questões sociais da educação; fomentamos o diálogo entre a Universidade e as escolas de Educação Básica e, ainda, ofertamos formação continuada aos professores da Educação Básica, sobretudo, àqueles que ensinam Matemática, procurando melhorar a sua prática de ensino.

Nesta direção, como explicam Vieira e Moreira (2018, p. 553), “a prática do professor de Matemática deve ser crítica e reflexiva, além disso, ele deve ser capaz de identificar as questões presentes no contexto social e na sala de aula com intuito de compreendê-las para poder intervir na realidade". Com este propósito, temos atuado com vistas a profissionalidade, a identidade, aos saberes, a qualificação do trabalho docente e, sobretudo, as condições dignas da docência de professores que ensinam Matemática.

\section{ESTRUTURAÇÃO DO PROJETO E DAS ATIVIDADES}

O Projeto empreendido pelo grupo de pesquisa DIEM, base da tessitura das experiências relatadas, foi estruturado e desenvolvido em distintas etapas e a metodologia utilizada nas etapas para os encontros de formação baseou-se na troca de experiências e na construção coletiva de conhecimentos sobre a formação de professores, nas didáticas específicas, na 
formação e prática docente, no acompanhamento da aprendizagem, na avaliação docente, na elaboração de materiais e no desenvolvimento de produtos educacionais e sociais que possam melhorar os índices de desempenho na educação e qualidade de vida das pessoas envolvidas.

Utilizamos a pesquisa colaborativa devido à sua relevância para a transformação da realidade dos envolvidos no Projeto, buscando, entre outras possibilidades,

[...] espaço para autoconhecimento e para novas produções; como contexto de empoderamento, mas também, e centralmente, como espaço de criticidade dos diferentes modos de ser profissional, de pensar e agir, na relação com outros; dos modos como entendem seus papéis na atividade com base em experiências sóciohistóricas acadêmicas e políticas (MAGALHÃES; LIBERALI, 2011, p. 299-300).

Nesse sentido, a pesquisa colaborativa, que "associa ao mesmo tempo atividades de produção do conhecimento e de desenvolvimento profissional” (DESGAGNÉ, 1998, p. 7), situa-se como "processo de indagação e teorização das práticas profissionais dos educadores e das teorias que guiam suas práticas" (MAGALHÃES; LIBERALI, 2011, p. 198), contribuindo, inegavelmente, para a melhoria qualitativa da realidade da atividade docente, que passa a ser feita com o professor e não para o professor, e com a sociedade e não somente para a sociedade. Passa a ter um sentido prático, uma vez que a teoria serve para fortalecer o desenvolvimento de serviços e produtos educacionais e sociais práticos.

Para a concretização da pesquisa estiveram presentes e, trabalhando continuamente, distintas pessoas envolvidas com a formação de professores que ensinam Matemática, com as práticas docentes, com as didáticas específicas e com o desenvolvimento socioeducacional, dando-lhe forte caráter extensionista, pois a cena da pesquisa proporcionou troca de conhecimentos, saberes e experiências. Tal envolvimento reverberou significativo impacto nas comunidades escolares contempladas (escolas públicas, universidades e institutos) que, a partir de então, vislumbramos a importância da socialização das experiências exitosas conquistadas, mostrando que é possível aliar ensino, pesquisa e extensão na busca pela melhoria da qualidade do ensino e aprendizagem da Matemática.

\section{EXPERIÊnCIAS E RELEVÂNCIA DAS ATIVIDAdes PARA A ÁREA E APLiCAÇão SOCIOEDUCACIONAL}

As atividades de pesquisa que desenvolvemos no âmbito do Projeto, no Diem e instituições parceiras, estão relacionadas à produção de conhecimento, devidamente disseminada em livros, artigos e eventos científicos, tendo como cerne os produtos sociais e educacionais desenvolvidos no seu interior. Assim, buscamos a interação entre os participantes (alunos de iniciação científica/projeto e de graduação; orientandos de mestrado e doutorado; 
professores de escolas públicas e demais parceiros) e a realidade vivenciada em seu cotidiano, promovendo constante troca de conhecimentos derivados de seu ambiente de vida, do trabalho e da escola (MAGALHÃES; LIBERALI, 2011; MARTINHO, 2020; MOREIRA, 2020a; b).

Consoante ao que propõe a referida formação docente, nosso Projeto buscou desenvolver pesquisas sociais e educacionais empregadas na formação de professores, contribuindo com a formação continuada e a prática docente, com as didáticas específicas e desenvolvimento de produtos educacionais de alta qualidade. Mais especificamente, atuamos com a formação de professores em regiões periféricas de Brasília, tendo como lócus prioritário as Regiões Administrativas do Distrito Federal, a Universidade de Brasília - UnB e os municípios da circunscrição da Região Integrada de Desenvolvimento do Distrito Federal e Entorno (RIDE), que, certamente, ecoam nos índices de formação dos professores e melhoria da qualidade da educação, com forte ressonância social.

O Projeto teve duração de 36 meses e as questões centrais foram: quais são os múltiplos olhares e contextos trazidos pelos componentes do Projeto enquanto dialogam no grupo de formação, para melhorar a prática de ensino para alunos da Educação Básica? Que experiências foram proporcionadas pelos membros do DIEM, enquanto formadores, aos estudantes da graduação e aos professores da Educação Básica, por meio das articulações, aprendizagens e a influência das práticas apresentadas sobre sua atuação, em especial, no que se refere ao desenvolvimento de produtos educacionais e sociais, no diálogo com o Projeto? Quais foram os diferentes conhecimentos adquiridos pelos participantes do Projeto durante as reuniões do grupo de formação, enquanto desenvolvem ações de ensino, pesquisa e extensão, nas questões relativas à educação e ao desenvolvimento social? Como a formação continuada aos professores da Educação Básica, inseridos no Projeto, melhorou a qualidade de vida das pessoas, por meio do desenvolvimento de investigações que atendam às demandas sociais e educacionais, mediante o desenvolvimento de produtos e serviços educacionais e sociais?

Responder a estas questões significou contribuir para a (re)organização didáticopedagógica da Educação Básica, uma vez que os atores sociais envolvidos neste processo carecem de esclarecimentos e auxílio para melhorarem pedagogicamente sua prática de ensino e aprendizagem. É, também, uma oportunidade de refletir sobre a complexa temática educacional, sobretudo, no que concerne à Educação, à Matemática, à Educação Matemática, à inclusão e à Educação Matemática em Direitos Humanos, na perspectiva da formação docente.

Diante dos objetivos e questões de investigação apresentados, observa-se a dimensão pretendida: desenvolver investigações sociais e educacionais empregadas na formação de 
professores, contribuindo com a formação continuada, com a prática docente, com as didáticas específicas e o desenvolvimento de produtos educacionais e sociais que possam melhorar os índices de desempenho na educação e qualidade de vida das pessoas das regiões circunvizinhas à realização do Projeto.

A possibilidade de desenvolvimento do Projeto, o que oportuniza a ascensão ao aprimoramento da pesquisa, não significa a conclusão de um ciclo acadêmico e nem o encerramento das aspirações de ser, e sim, lançar desafios da vida em direção à busca incessante do conhecimento, até porque passamos a ter uma responsabilidade maior e mais ampla frente ao que vimos fazendo há anos na e para a Educação: realizar pesquisas que tenham reverberação social e educacional!

Ora, se o chão da escola sempre foi nosso ponto de partida e, sendo também compreendido como o principal lugar capaz de mudar a realidade de uma comunidade, é nele e para ele que temos de retornar os resultados do que se é produzido. E, é a partir dele que temos a possibilidade de fazer pesquisa como esta, capaz de mudar a realidade social e educacional das comunidades envolvidas.

A possibilidade de construir produtos e serviços, como formação continuada, materiais instrucionais, tecnologia assistiva, palestras, oficinas, publicações, entre outras, nas esferas educacionais e sociais, ressoam na melhoria da qualidade de vida das pessoas de um modo geral, visto que podem melhorar a formação dos futuros e atuais professores, sobretudo, dos que ensinam Matemática. Além disso, podem elevar o desempenho dos estudantes, diminuir os índices de repetência e evasão escolar, ser uma rica oportunidade de se mostrar que ensino, pesquisa e extensão devem andar juntos e ser uma oportunidade de se fazer trabalhos de graduação, dissertação de mestrado e tese de doutorado com impacto direto na sala de aula.

Isto significa que os diferentes produtos e serviços educacionais tornam possível mudar a realidade de uma comunidade, pois são momentos de aprendizagem mútua, com fortíssima ressonância social e educacional, de convergência da sabedoria e do conhecimento adquirido: sabedoria pelas experiências acumuladas durante as trajetórias de nossas vidas; conhecimento pelo acúmulo de informações recebidas, trabalhadas, reelaboradas e devolvidas durante a execução do Projeto.

\section{Parcerias estabelecidas}

Nosso Projeto teve distintas instituições parceiras, localizadas no Distrito Federal e fora dele, descritas a seguir. A gestão compartilhada das atividades, tendo o seu líder como pilar, 
trouxe resultados sólidos, com eco na produção de muitos trabalhos de impacto social e educacional.

O parceiro Dzeta Investigações em Educação Matemática (DIEM) mostrou-se muito importante e imprescindível na elaboração das atividades. O DIEM é um Grupo de Pesquisa que encontra-se certificado pela UnB e pelo Diretório de Pesquisa do CNPq, tendo o seu líder e sua vice-líder como coautores deste texto e muitos pesquisadores nacionais e internacionais! Já produziu 46 trabalhos publicados em periódicos; 25 trabalhos publicados em anais de eventos; 16 capítulos de livros e cinco livros. Além disso, 12 dissertações de Mestrado e uma tese de doutorado já foram defendidas sob sua tutela, além de várias outras pesquisas em andamento, com vistas à defesa e publicação em breve.

O DIEM desenvolve atividades em diferentes contextos, por exemplo: na UnB; nas escolas públicas do DF; na Universidade Estadual de Goiás - UEG; no Instituto Federal de Brasília - IFB; na SEEDF, entre outras instituições afora. A parceria com o DIEM foi crucial, haja vista que temos o compromisso com seu desenvolvimento e com a continuidade permanente dos trabalhos em desenvolvimento. Obviamente que a grande produção e participação dos mais de 25 membros (nacionais e internacionais) teve ressonância direta nas investigações.

A parceira Secretaria de Estado de Educação do Distrito Federal (SEEDF) apresenta, atualmente, uma estrutura complexa, com 683 escolas (urbanas e rurais); 538.659 alunos; 34.882 professores e orientadores educacionais e 17.308 assistentes. Possui, ainda, uma Subsecretaria de Formação Continuada dos Profissionais da Educação, chamada de EAPE, que não consegue ofertar formação a todos os servidores, em especial aos professores, atores de nosso Projeto de Pesquisa (DISTRITO FEDERAL, 2019). Foi o lócus principal de investigação, pois nela encontram-se a maior parte dos participantes da pesquisa, os professores da Educação Básica. A contribuição assentou-se na perspectiva de abertura para realizarmos as investigações em seus espaços escolares, quando ofertamos, inclusive, formação continuada aos participantes, contribuindo para o desenvolvimento pesquisas sociais e educacionais. O Projeto contou com 21 participantes. Ao todo, foram realizadas formações no CEF Rio Preto; CEF Cerâmicas Reunidas Dom Bosco; Escola Classe 09 de Planaltina; no CEF CASEB e na Escola Classe 01 de Ceilândia.

Por sua vez, a Fundação de Apoio à Pesquisa do Distrito Federal (FAPDF) financiou a primeira parte de nosso Projeto de Pesquisa, que contou com 21 participantes diretos; mais de 200 participantes indiretos e resultou em 18 produções (artigos, livros, capítulos e 
comunicações científicas em eventos nacionais e internacionais) e 15 orientações de iniciação científica, mestrado ou doutorado.

A Faculdade de Educação da Universidade de Brasília (FE/UnB) foi o pilar no desenvolvimento das atividades! Embora saibamos que a UnB foi a Instituição Executora do Projeto, é preciso destacar que a FE/UnB, como unidade autônoma no âmbito da Universidade, hospedou nosso Projeto. Por termos forte atuação na Pós-Graduação em Educação, utilizamos não apenas seus espaços físicos (salas, laboratórios, gabinetes), mas, também, as turmas de graduação, como embriões/laboratórios do Projeto, e os orientandos de Mestrado e Doutorado, que compõem o Projeto, receberam a formação e levaram às escolas participantes.

O parceiro Instituto Nacional de Estudos e Pesquisas Educacionais Anísio Teixeira (INEP), por sua vez, possui, em sua estrutura, distintas diretorias e funções. Uma delas, diz respeito à divulgação dos resultados do Sistema Nacional de Avaliação da Educação Básica (Saeb) e do Programa Internacional de Avaliação de Estudantes (Pisa), que são apresentados em forma de relatórios consolidados, boletins de desempenho ou sistemas de acesso a resultados como o painel educacional, além, é claro, de dados abertos com os microdados, sinopses estatísticas, indicadores educacionais, Inepdata, mapa da coleta, que oferecem informações que podem ajudar a interpretar a educação brasileira, principalmente as avaliações em larga escala (ALVES; FERRÃO, 2019).

Preocupados com as formações dos professores da Educação Básica, que acessam dados importantes das avaliações em larga escala, a parceria com o INEP foi importante porque desde os gestores governamentais de políticas públicas da educação, passando pelas equipes pedagógicas das escolas até os professores, têm dificuldades para acessar, interpretar, analisar e utilizar os resultados das avaliações nos diferentes contextos educacionais. Se, nesta perspectiva, as avaliações em larga escala têm sido assunto de grande interesse de estudiosos brasileiros no decorrer dos últimos anos, tanto no cenário nacional quanto internacional (ORTIGÃO, 2018), seus dados podem possibilitar o redirecionamento de uma série de decisões, sobretudo quando se quer valorizar a Ciência e a Educação.

A dinâmica do grupo concentrou-se em realizar formação dos seus membros no âmbito do DIEM, da FE/UnB e demais parceiros. É importante destacar que, embora não sendo parceiros oficiais, o Instituto Federal de Goiás (IFG) - Campus Formosa, o Instituto Federal de Brasília (IFB), a CRE-Formosa e a Universidade Estadual de Goiás (UEG) foram beneficiados. 


\section{ISSN: 2526-2149}

\section{DESENVOLVIMENTO DA PESQUISA E EXECUÇÃo DAS ATIVIDADES}

Considerando o enorme arcabouço teórico-metodológico envolvido no Projeto, com objetivos, questões de investigação e metas significativamente alvissareiros, foi preciso delinear as etapas de desenvolvimento da investigação (MOREIRA; SALLA, 2018; FRAZ; HOTT; MOREIRA; RODRIGUES, 2019; TEIXEIRA; MOREIRA, 2020; FERREIRA, 2020; VIEIRA; MOREIRA, 2020a; b; c). Obviamente, não é possível detalhar e/ou esmiuçar cada uma das etapas, haja vista que foram destrinchadas em etapas menores para alcançarmos os resultados esperados. Então, a seguir, apresentamos as etapas macro, que foram os guardachuvas das etapas na perspectiva micro.

$1^{a}$ etapa: Preparação do grupo de formação - nesta etapa, foram desenvolvidas atividades de preparação do grupo para o trabalho que realizado nas fases seguintes. Foram previstos muitos encontros de sensibilização para a importância e qualificação do Projeto, bem como possibilitar sensações capazes de influenciar e sensibilizar atitudes humanizadas em relação ao ensino e aprendizagem e à formação dos professores. Estiveram envolvidos os parceiros do Projeto; o Coordenador e os oficineiros (alunos da iniciação científica/projeto, de mestrado e doutorado). Além das dinâmicas de grupo, foram planejados encontros para a apresentação de palestras sobre temas relacionados a cada bloco, realizadas por professores parceiros, que possuem experiências com as temáticas de cada oficina/formação.

$2^{\mathrm{a}}$ etapa: Encontros de Formação - etapa em que foram realizadas oficinas de formação sobre os conteúdos a serem trabalhados, separadas por blocos, e materiais pedagógicos que podem ser utilizados em cada oficina e nos blocos, principalmente para os alunos inseridos no Projeto. Também, foi o momento de começar a pensar, discutir e avaliar o tipo de produto e serviço educacional a ser desenvolvido. Participaram destes momentos, o Coordenador do Projeto e os oficineiros (alunos da iniciação científica/projeto, de mestrado e doutorado).

$3^{\text {a }}$ etapa: Realização de oficinas na graduação - nesta etapa, os oficineiros realizaram as oficinas, de acordo com planejamento bastante estruturado, nas turmas de graduação da UnB (Pedagogia e Matemática, por exemplo), a fim de praticar e melhorar o processo para depois irem às escolas replicarem aos professores. Os produtos e serviços já estavam definidos e os oficineiros avaliaram sua viabilidade nas turmas de graduação.

$4^{\mathrm{a}}$ etapa: Realização de oficinas nas escolas participantes - etapa em que os oficineiros, acompanhados do supervisor do Projeto, replicaram as oficinas aos professores das escolas envolvidas no Projeto, bem como explicaram os objetivos e as metas para cada uma das oficinas 
e, para além disso, apresentaram possíveis produtos educacionais e sociais que podem melhorar o processo de ensino e aprendizagem.

5 a etapa: Acompanhamento em sala de aula - esta foi uma etapa crucial e, talvez, a mais importante! Neste momento, os professores de cada uma das escolas participantes do Projeto aplicaram as atividades em suas salas de aula e fizeram a observação do desenvolvimento da atividade elaborada em cada um dos blocos, sempre sendo auxiliados por um dos oficineiros. Desta forma, toda escola participante teve acompanhamento das atividades realizadas.

$6^{\text {a }}$ etapa: Avaliação da aplicação das atividades em sala de aula - esta etapa envolveu a avaliação da aplicação das atividades, com o respectivo material, produto ou serviço em sala de aula, buscando trazer os seus pontos fortes e fracos, bem como compartilhar os conhecimentos adquiridos e apresentar as sugestões de melhoria em todo o processo, que se repetiu tantas vezes quantas foram necessárias.

$7^{\text {a }}$ etapa: Apresentação e análise dos resultados - nesta etapa, já na Universidade, os oficineiros voltaram para o grupo de formação e socializaram os dados coletados. Foi o momento de apresentar os dados, discutir os resultados e produzir, de fato, os trabalhos que ancoraram os produtos e/ou serviços educacionais e/ou sociais produzidos.

$8^{\text {a }}$ etapa: Elaboração de trabalhos - nesta e nas etapas anteriores, a depender do tipo de trabalho, os orientandos produziram os trabalhos de conclusão de curso, seja de iniciação científica, dissertação de mestrado ou tese de doutoramento. Os dados foram adquiridos no convívio escolar e internalizados de acordo com os interesses do Projeto. Contudo, as análise ultrapassam a mera ideia de reprodução e transmissão de conteúdos, cujo resultado é uma atividade interativa do espaço onde os atores sociais atuam uns sobre os outros fazendo valer suas ações (argumentação), assumindo formas de instituição e representação intelectual (subjetividade), tornando como verdade um determinado fenômeno (julgamento), até culminar com a realização de uma pesquisa que tenha ressonância social e educacional, como tem sido!

$9^{a}$ etapa: Socialização dos resultados - em cada etapa e na medida em que os orientandos foram às defesas, foram feitas as socializações parciais dos resultados, com todos os produtos e serviços devidamente aprovados e publicizados.

Este modelo proposto teve como objetivos acompanhar de perto e continuamente os professores e suas respectivas salas de aula; realizar reflexões conjuntas sobre os impactos e realidades encontradas; utilizar diagnósticos para agir sobre as dificuldades dos professores; compartilhar experiências de professores da rede pública; instituir um grupo de pesquisa comprometido com o processo de ensino e aprendizagem; ofertar formação desde a graduação 
à pós-graduação e, por fim, apresentar à sociedade materiais capazes de melhorar a qualidade da educação e da vida das pessoas.

Similarmente aos nossos estudos anteriores (MOREIRA, 2012; 2014; 2015; 2016; 2020a; b; MOREIRA; MANRIQUE, 2014; 2019; MANRIQUE; MARANHÃO; MOREIRA, 2016a; b; MOREIRA; SALLA, 2018; TEIXEIRA; MOREIRA, 2020; TEIXEIRA; PAIVA; MOREIRA, 2018), utilizamos múltiplos instrumentos de recolha de dados, tais como roteiros de entrevista semiestruturada; roteiros de observação; questionários; diários de bordo; planilhas; cadernos de anotações; gravações; observações; elaboração de materiais; disparadores temáticos; experimentação, entre outros.

No azo, julgamos pertinente esclarecer que a opção pela utilização de múltiplos instrumentos de coleta de dados, objetiva garantir a fidedignidade e precisão às respostas obtidas (referenciar com autores esse entendimento sobre a multiplicidade de instrumentos de coleta de dados), bem como propiciar condições para a fluidez dos discursos dos indivíduos participantes da investigação, uma vez que desenvolver pesquisas sociais e educacionais empregadas na formação de professores, com vistas ao desenvolvimento de produtos educacionais e sociais que possam melhorar os índices de desempenho na educação e qualidade de vida das pessoas, requer expertise e um olhar científico com maturidade apurada para os serviços e/ou produtos desenvolvidos.

\section{Potencial inOVAdor das ATIVIDAdes DESENVOLVIDAS PARA O ENSINO, A PESQUiSA E A EXTENSÃO}

As atividades de pesquisa, neste Projeto, coligadas com o ensino e a extensão, relacionaram-se à produção de conhecimento, devidamente disseminada em livros, artigos e eventos científicos, tendo como cerne os produtos sociais e educacionais desenvolvidos no seu interior. Assim, busca-se a interação entre os participantes (alunos de iniciação científica/projeto e de graduação; orientandos de mestrado e doutorado; professores de escolas públicas e demais parceiros) e a realidade que eles vivenciam em seu cotidiano, promovendo constante troca de conhecimentos oriundos de seu ambiente de vida, do trabalho e da escola.

Deste modo, as atividades de aplicação propostas estão associadas ao cotidiano pedagógico de professores das escolas, cujo público está inserido em áreas de características urbanas ou rurais. Envolveram, ainda, a aplicação de oficinas pedagógicas e ampla formação de professores que possibilitaram a construção coletiva do conhecimento e o compartilhamento de experiências de professores da rede pública de ensino do Distrito Federal e arredores. 
A Educação Matemática, na acepção d'ambrosiana, vem discutindo e trabalhando com os conhecimentos adquiridos no meio socioetnocultural que, mesmo não formalizados e nem aceitos cientificamente, emergem no cotidiano do homem, seja na cidade, no campo ou outros grupos étnicos (D’AMBRÓSIO, 2002; 2018).

De forma consentânea, acreditamos que a junção dos conhecimentos da Educação Matemática com a Educação Inclusiva e a Educação Matemática em Direitos Humanos (PADILHA, 2005; GENTILI, 2009; CANDAU et al., 2013; VIEIRA; MOREIRA, 2020a; b; c), seja capaz de dar voz às minorias que, em diversos casos, além de estarem marginalizadas, não têm a escola como elemento de emancipação social, uma vez que os saberes produzidos pelas (e nas) camadas populares não são reconhecidos e valorizados “[...] por não serem produzidos por aqueles grupos que são legitimados em nossa sociedade como os produtores de ciência, ficam silenciados, num processo de ocultamento que certamente produz relações de poder muito particulares” (KNIJNIK, 1997, p. 38). Assim, esta educação, “[...] exige que se parta do contexto concreto/vivido para se chegar ao contexto teórico, o que requer a curiosidade epistemológica, a problematização, a rigorosidade, a criatividade, o diálogo, a vivência da práxis e o protagonismo dos sujeitos" (FREIRE, 1995, p. 29).

As práticas educativas realizadas e divulgadas no Projeto não são restritas à dimensão cognitiva, mas fortemente amparadas nas dimensões política, social e histórica. Os processos formativos são voltados para a construção de uma sociedade mais justa para todos e para a inclusão, ou seja, buscam a formação integral dos envolvidos no que tange a justiça social, a autonomia, a solidariedade, o respeito às diferenças e a transformação social. Isto pressupõe uma mudança do papel da matemática e do professor de matemática para que seja possível a “construção do pensamento crítico sobre as injustiças que assolam a sociedade, essas que, muitas vezes, encontram-se respaldo na própria racionalidade matemática" (VIEIRA; MOREIRA, 2020b, p. 639). Tornando o docente agente sociocultural e político, que reconhece a diversidade, promove práticas educativas pautadas na inclusão, na autonomia e no empoderamento (VIEIRA; MOREIRA, 2020c).

Ora, se o processo de ensino e aprendizagem em geral foca na inovação, principalmente em tempos de pandemia e isolamento social, acreditamos que os produtos e serviços elaborados no seio da Universidade, mesclando teoria e prática, como é o nosso caso, podem ser um rico instrumento de inovação, tanto no processo de formação continuada dos professores participantes do Projeto, quanto na necessidade de reinvenção e drible das condições atuais de 
ensino e aprendizagem, reverberando em uma condição fundamental para a competitividade socioeducacional, tanto ao nível brasileiro quanto global.

Se a escola, como instituição social que é, é a grande responsável por realizar a mediação entre o indivíduo e a sociedade, que prepara o primeiro para enfrentar e contribuir para os problemas da segunda, as inovações de processos e de produtos nas organizações escolares, sobretudo, demonstram a necessidade de demandar alterações nos modelos educacionais atuais. Para tanto, aliamos teoria e prática, o que, por si só, já demonstra grande capacidade de ajudar a conhecer a realidade educacional, hoje assentada em uma via de mão única, que muitas vezes que não dá voz a todos os atores educacionais ali envolvidos, cujas características do professor bem formado são basilares para planejar o resultado gerado por esse processo de mudança social e educacional que almejamos (MOREIRA, 2020b).

Há muito se ouve falar que o Brasil necessita dar um salto na educação. Porém, há de se questionar a relação escola versus inovação e, então, compreender o resultado efetivo de nossa capacidade para o desenvolvimento socioeducacional do País, tornando possível "o desenvolvimento do potencial dos indivíduos e a formação não somente para o trabalho, mas para a vida em sociedade" (FRAZ; HOTT; MOREIRA; RODRIGUES, 2019, p. 76). Por isso, entendemos que nosso Projeto, ao coligar universidade, formação inicial, pesquisadores e professores da educação básica, revelou-se altamente inovador do ponto de vista teóricoprático, pois, ao final, os produtos e serviços desenvolvidos, refletirão, certamente, na qualidade da educação, porque "trabalho e educação são atividades especificamente humanas. Isso significa que, rigorosamente falando, apenas o ser humano trabalha e educa" (SAVIANI, 2007, p. 152).

Nesse sentido, enxergamos que a investigação apresenta grande aporte social, sobretudo na sua inovação com relação ao processo de ensino e aprendizagem, haja vista que pode melhorar a qualidade da educação (na Matemática, na inclusão e nos Direitos Humanos), por meio do desenvolvimento de tecnologias sociais e educacionais, aprimorando o processo de formação continuada. Buscamos dar voz aos docentes que atuam e atuarão na educação de aprendizes da escola regular e, também, da Educação Especial.

\section{Produtos, Processos e SERVIÇOS SOCIOEduCACIONAIS PARA O DESENVOLVIMENTO LOCAL}

Privilegiamos uma visão sistêmica, dinâmica e multifacetada no Projeto, focalizando, principalmente, os processos e as interações entre os participantes e o ambiente em que estão 
inseridos (universidades, escolas, órgãos governamentais e sociedade), pois “[...] os fenômenos educativos não podem ser pesquisados fora da interação dialógica entre teoria e prática" (ESTEBAN, 2002, p. 10).

A melhoria na educação pública perpassa, necessariamente, pela boa formação dos seus professores, principalmente no que diz respeito à formação continuada. Intenciona ofertar formação aos atores envolvidos (pesquisadores; mestrandos; doutorandos; alunos da graduação e professores da Educação Básica), abrangendo oficinas; experimentações; serviços (estudo, orientação e planejamento); elaboração de materiais instrucionais; produtos sociais e tecnológicos, tais como manuais, instrumentos e conhecimento, culminando com o desenvolvimento de publicações de alto nível (artigos, capítulos de livros, livros, comunicações científicas, dissertações e teses), o que justifica as demandas de sua realização.

Logo, demandar a melhoria nos processos de ensino e aprendizagem, no âmbito da pesquisa, ensino e extensão, requer, como dito, coligar teoria e prática, com repercussão direta na qualidade da educação, pois, percebe-se, pela robustez investigativa diante dos resultados alcançados, persistência, estudo e informação, com forte destaque para a educação.

Consentaneamente, a possibilidade que se abre para o desenvolvimento de pesquisas como essa, provoca a busca e o desejo por outras conquistas e realizações, principalmente porque temos a responsabilidade de atuar e interferir nas práticas sociais e educacionais voltadas às comunidades mais necessitadas, onde pretendemos contribuir para a efetivação do processo de socialização de experiências exitosas, pois a atuação docente "deverá ter, acima de tudo, uma pertinência socioprofissional, deverá aderir à prática mais do que à estética da argumentação formal” (LESSARD-HÉBERT; GOYETTE; BOUTIN, 1994, p. 87).

\section{RESUltados AlCANÇADOS}

Por vezes a escola tem se mostrado incapaz de atrair os estudantes para o processo de aprendizagem da Matemática e "o desinteresse do aluno desponta na frente, sendo associado a outros elementos como dificuldade de aprendizagem e conteúdos desinteressantes [...]” (ALVES-MAZZOTTI, 2010, p. 7-8). Esse fato pode ser procedente do formalismo com que este conhecimento ainda é tratado no espaço da sala de aula, parte dinâmica de um espaço plural como é a escola (FERREIRA, 2020).

Para atrair os estudantes e despertar o desejo de aprender, a transposição didática deve ser feita de modo que possa aliar o formalismo, próprio da Matemática, às necessidades e interesses do estudante, ou seja, construir os conceitos matemáticos a partir da realidade escolar, 
favorecendo o processo de compreensão e participação ativa dos estudantes. Neste sentido, Pais (2006, p. 11) enfatiza que "a tentativa de separar a objetividade da subjetividade caracteriza um dos tipos de contratos pedagógicos mais tradicionais do ensino da Matemática, em que compete ao professor a tarefa de colocar questões e ao aluno a tarefa de respondê-las".

Esse tipo de contrato didático necessita ser revisto e substituído por práticas contextualizadas e que contemplem, não apenas os aspectos cognitivos, mas também os afetivos e contextuais (BRITO, 2005; VILA; CALLEJO, 2006), uma vez que os modos de relação e as necessidades dos estudantes têm sido modificados pelos processos de informatização e tecnologia, que dispõe de alternativas variadas à Educação, apresentando novos ritmos e dimensões a tarefa de ensinar e aprender (KENSKI, 1998). Importante ressaltar que todo esse conhecimento tecnológico é ancorado em procedimentos e algoritmos matemáticos que raramente são explorados na escola.

A educação precisa romper com o paradigma da educação fragmentada, ensino conteudista, do cientificismo, da desvalorização dos saberes desenvolvidos para além dos espaços acadêmicos. Em contrapartida, deve atuar para resgatar a dimensão subjetiva, afetiva e criadora do processo educativo (MANTOAN, 2015, p. 13).

Parte dos problemas que atualmente justificam o fracasso dos processos de ensino e aprendizagem da Matemática parece ser originado na divergência entre as vivências dos estudantes e o que a escola oferece. Para tanto, o grupo de pesquisa apresenta atividades que vêm ao encontro à necessidade de reorganização do trabalho pedagógico com enfoque no desenvolvimento de habilidades que permitam aos estudantes trabalharem em colaboração com seus pares e atuar de forma autônoma frente aos problemas do cotidiano. Para Martinho (2020, p. 7), "a cultura profissional colaborativa e de aperfeiçoamento contínuo é essencial para a promoção do sucesso de todos os alunos da comunidade envolvida". De fato, como afirmado por Vigotsky (2001), a aprendizagem deve ter origem nas relações e práticas sociais.

A seguir, apresentamos as atividades desenvolvidas, considerando as etapas descritas no item "desenvolvimento da pesquisa e execução das atividades" deste texto. Na primeira e segunda etapas, foram feitas a preparação do grupo de formação e os encontros de formação, respectivamente, pelos membros do DIEM, nas dependências da FE/UnB. 
Figura 1 - Preparação do grupo de formação e encontros de formação (2018 a 2020)
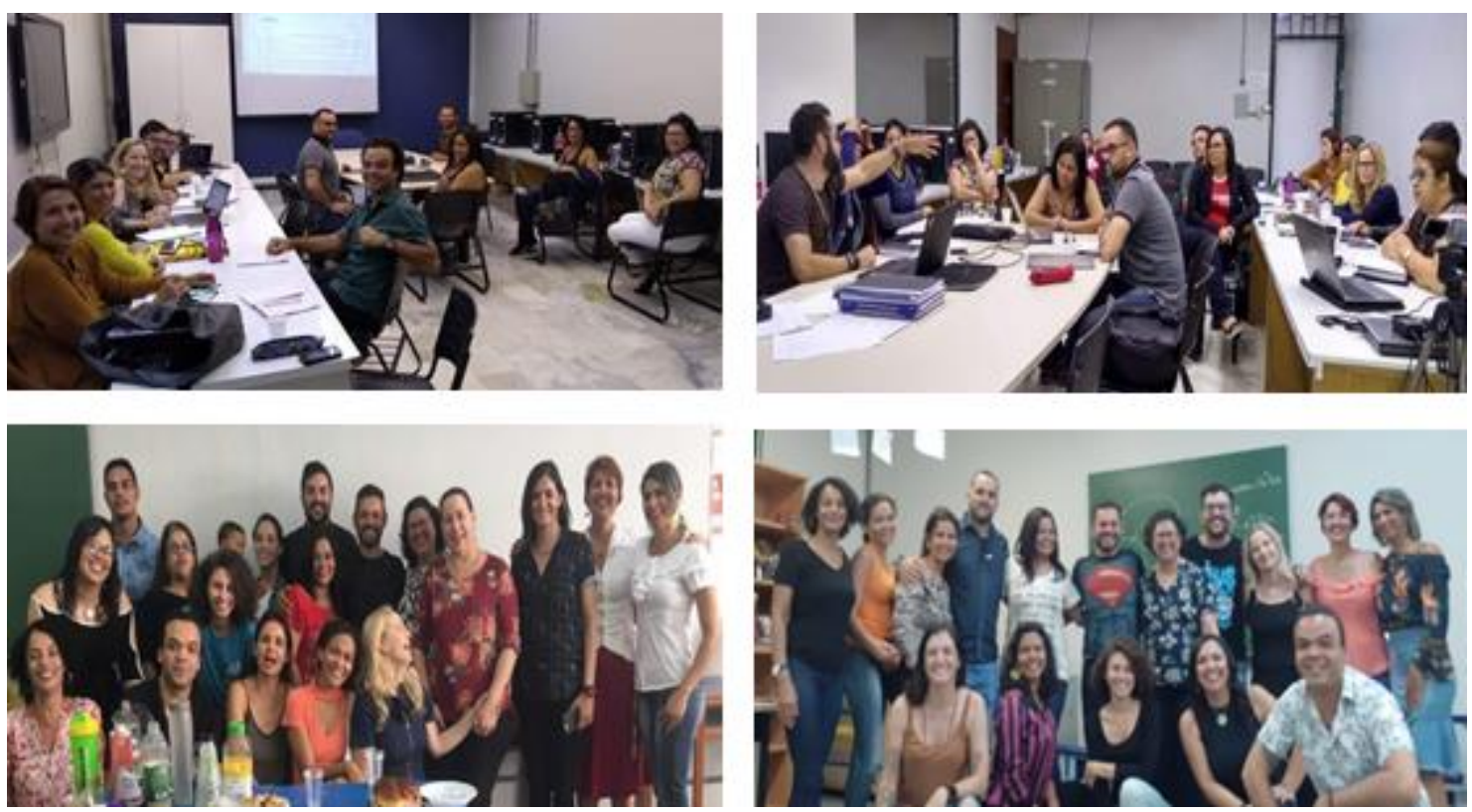

Fonte: Arquivos do DIEM.

Como pode ser observado na Figura 1, foram realizadas as atividades de preparação do grupo, por meio de reuniões, dinâmicas de grupos e seleção dos conteúdos abordados por cada formador. Durante a formação dos formadores, foram debatidos distintos assuntos (quais por exemplo?), objetivando clarear as dúvidas quanto aos conteúdos, os materiais pedagógicos utilizados em cada oficina, a aplicação das atividades nas turmas de graduação (piloto) e explicações diversas sobre o processo adotado.

$\mathrm{Na}$ terceira etapa, foram realizadas as oficinas nas turmas de graduação, na FE/UnB. As oficinas foram realizadas pelos formadores, tendo como objetivo um estudo piloto, haja vista que a etapa seguinte foi a aplicação aos professores nas suas respectivas escolas. 
Figura 2 - Aplicação das atividades nas turmas de graduação: FE/UnB (2018 a 2020)
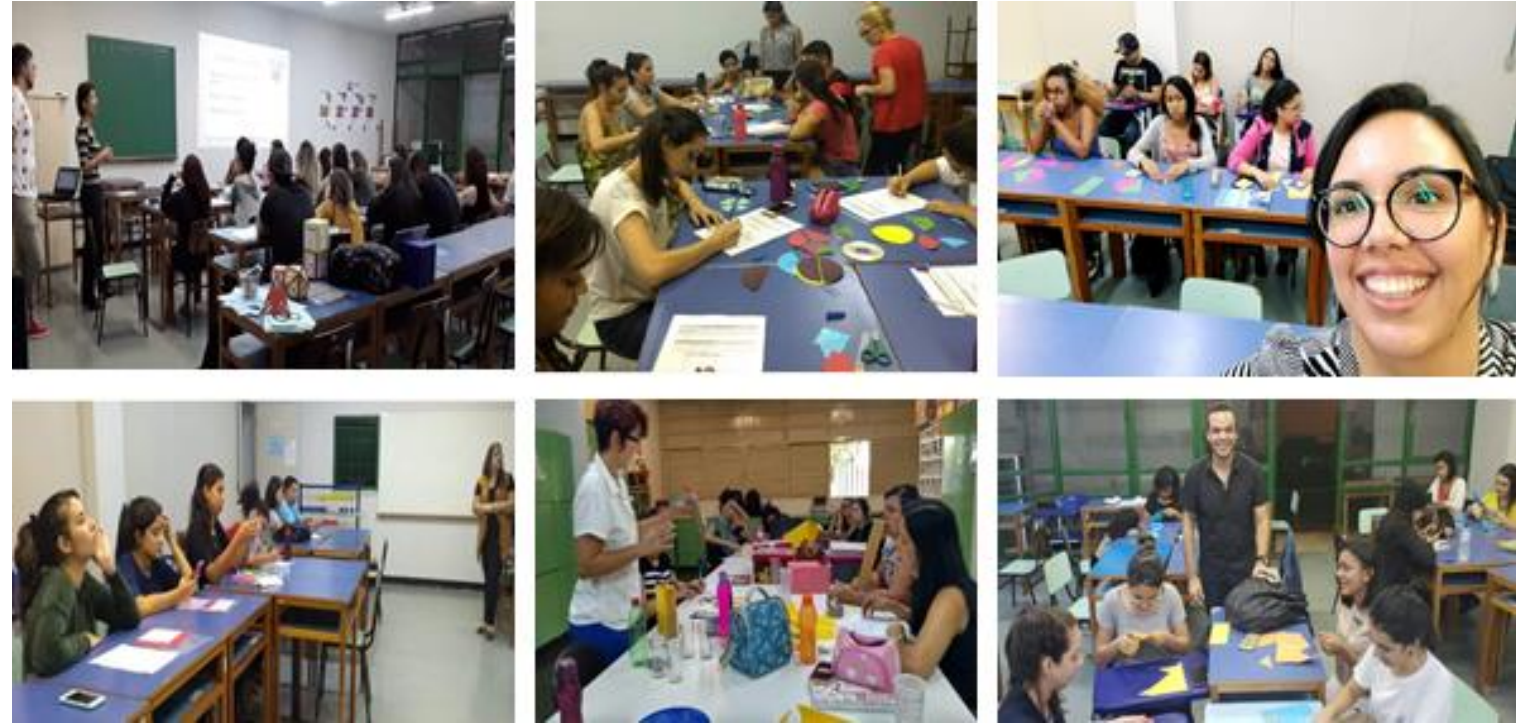

Fonte: Arquivos do DIEM.

A Figura 2 revela distintos momentos de realização das oficinas ofertadas aos futuros professores. É possível observar a diversidade e riqueza de materiais utilizados, bem como o envolvimento de formadores e formandos. O objetivo foi praticar o/no processo de ensino e aprendizagem da Matemática para depois irem às escolas replicarem aos professores, quando os oficineiros avaliaram sua viabilidade nas turmas de graduação e realizaram possíveis mudanças nos planejamentos. Entendemos que "o caráter profissional relacionado à formação pedagógica dos futuros professores que ensinarão Matemática necessita coligar a importância dos elementos formadores presentes nos conteúdos específicos de Matemática e de formação pedagógica" (MOREIRA, 2019, p. 46), pois, para isso, "compreender a importância da díade estabelecida entre a Educação Matemática e a Matemática” faz-se necessário e atual!

A quarta etapa caracterizou-se pela realização de oficinas para os professores das escolas participantes. Foi o momento mais importante, cuja formação dos professores revelouse latente e necessária, principalmente porque o "inflamado discurso sobre a necessidade de dialogar acerca da formação do professor que ensina Matemática, em qualquer nível de ensino, não é novo" e, ademais, "requer abertura e necessidade de experimentar novas formas de ensinar e aprender, desconstruindo práticas assentadas em velhos valores pedagógicos" (MOREIRA, 2019, p. 45). 
Figura 3 - Aplicação das atividades aos professores das escolas participantes (2018 a 2020)
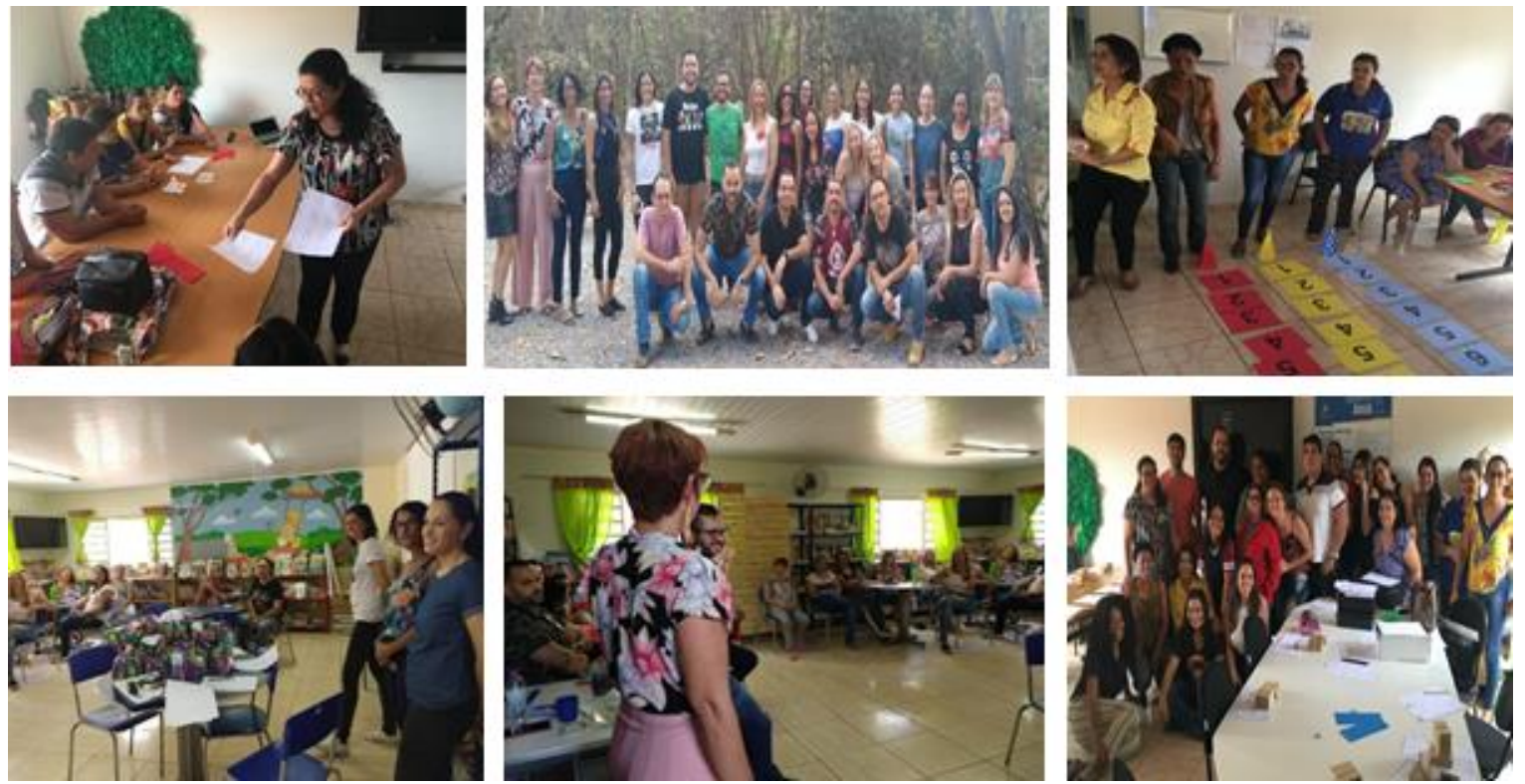

Fonte: Arquivos do DIEM.

A Figura 3 é reveladora! Em todas as escolas e demais espaços contemplados com as atividades, foi possível observar a lacuna existente na formação dos professores. $\mathrm{Na}$ oportunidade, os formadores explicaram os objetivos e as metas para cada uma das oficinas e, ainda, apresentaram possibilidades pedagógicas para trabalharem cada um dos conteúdos abordados, o que pode melhorar o processo de ensino e aprendizagem da Matemática.

$\mathrm{Na}$ quinta etapa, as atividades foram aplicadas na sala de aula dos professores das escolas públicas participantes. Após o processo de formação, os professores aplicaram as atividades em suas respectivas salas de aula.

Figura 4 - Aplicação das atividades aos alunos das escolas participantes (2018 a 2020)
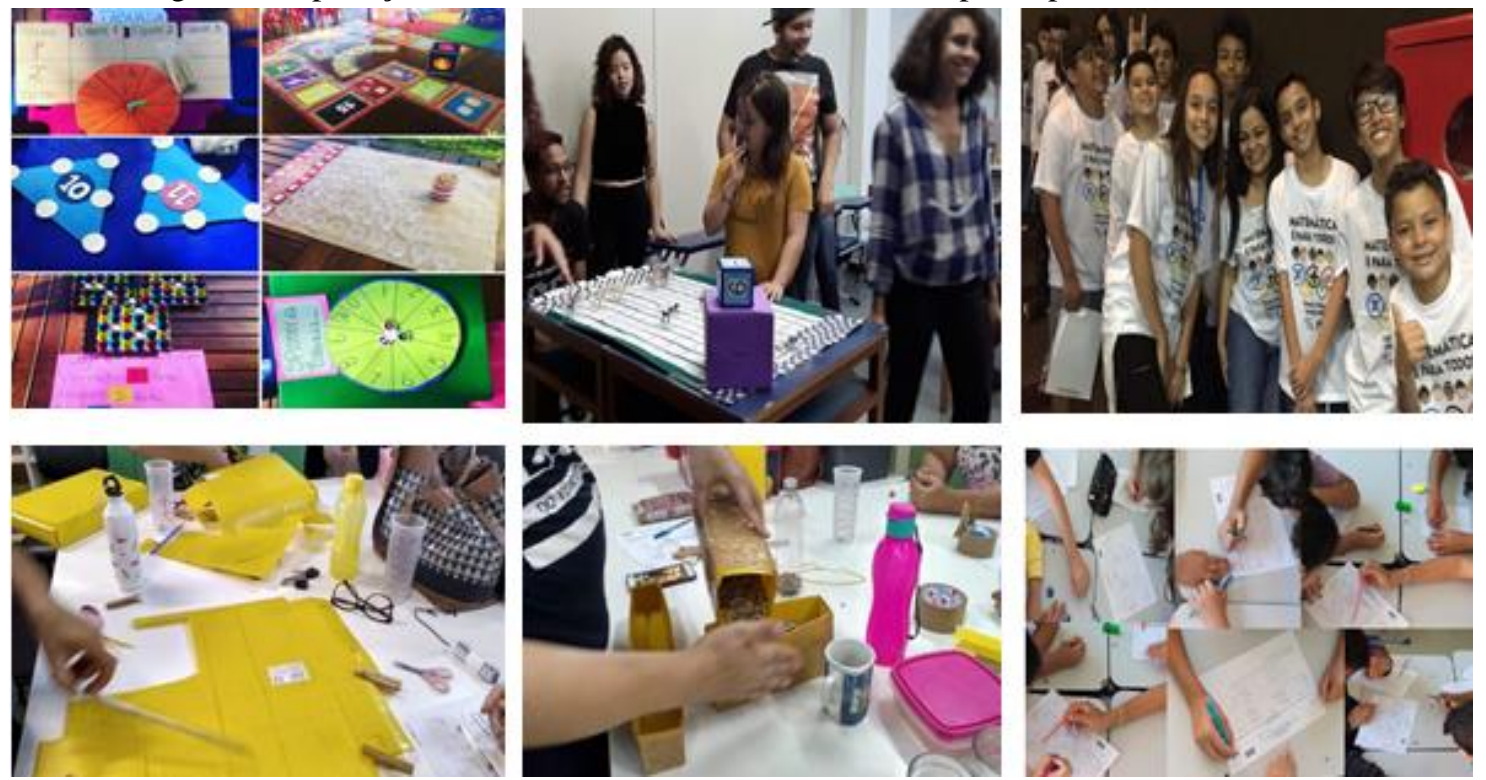

Fonte: Arquivos do DIEM.

Instituto Federal de Mato Grosso - Campus Confresa

Revista Prática Docente. v. 6, n. 1, e001, jan/abr 2021. 
Evidentemente os resultados foram muito significativos e os docentes envolvidos nos momentos de realização das atividades trouxeram os pontos fortes destas e sugeriram melhorias em todo o processo, o que se repetiu de acordo com as necessidades.

Consideramos que, para além das habilidades cognitivas e pedagógicas, as atividades promoveram e desenvolveram o diálogo, a discussão e as interações entre os estudantes. "Tratase de colocar os alunos, tão frequentemente quanto possível, em situações de confronto, de troca, de interação, de decisão, que os force a se explicitar seus pensamentos, se justificar, argumentar, expor ideias, dar ou receber informações para tomar decisões" (PERRENOUD, 1999, p. 99).

As atividades desenvolvidas pelos membros do DIEM, para além da coleta de informações sobre o trabalho pedagógico que vem sendo desenvolvido nas escolas do DF, objetivaram servir de base para outras proposições, podendo ser adaptadas a distintos objetos do conhecimento e situações problema, gerando aprendizagens que sejam significativas, conforme destacam Moreira e Manrique (2019, p. 75):

Para que a aprendizagem significativa ocorra, é preciso que duas condições sejam satisfeitas: o material de aprendizagem (livros, aulas, material pedagógico e humano) deve ser potencialmente significativo e o aprendiz deve apresentar uma predisposição para aprender, ou seja, que o aprendiz tenha em sua estrutura cognitiva ideias-âncora relevantes com as quais o referido material possa ser relacionado.

Importa destacar que, desde a preparação das oficinas, perpassando pela formação dos formadores, aplicação nas turmas de graduação (projeto piloto), culminando com formação dos professores e, consequente, repasse às salas de aula, os seguintes conteúdos matemáticos foram trabalhados: contagem, operações, resolução de situações problemas, sistema de numeração, sistemas de medidas, expressões numéricas, frações, sólidos geométricos, área e volume, utilização de origami e tangram, entre outros conteúdos (MOREIRA, 2020a; TEIXEIRA, MOREIRA, 2020; SOUZA, 2019; PAIVA, 2019).

Outros temas importantes também foram contemplados em todo o processo, uma vez que pensamos nos alunos de um modo geral, com ou sem necessidades específicas. Em particular, a inclusão de estudantes com NEE em aulas de Matemática com destaque para estudantes que apresentam comportamento de altas habilidades/superdotação, além da diversidade e direitos humanos em aulas de Matemática. Esses temas foram debatidos e resultaram em fortes apelos para uma formação mais complementar dos professores das escolas e demais parceiros envolvidos, haja vista a escassez de ações que oportunizem tais debates. 


\section{REFERÊNCIAS}

ALVES, Maria Teresa Gonzaga; FERRÃO, Maria Eugénia. Uma década da Prova Brasil: evolução do desempenho e da aprovação. Estudos, Avaliação e Educação, São Paulo, v. 30, n. 75, p. 688-720, 2019. Disponível em:

http://publicacoes.fcc.org.br/ojs/index.php/eae/article/view/6298. Acesso em: 15 jul. 2020.

ALVES-MAZZOTTI, A. J. A. Fracasso escolar: representações de professores e alunos repetentes. REUNIÃO ANUAL DA ANPED, 26, 2010. Anais [...]. Poços de Caldas, MG: ANPED, 2010. p. 1-17. Disponível em:

http://www.anped.org.br/reunioes/26/trabalhos/aldajudith--alvesmazzotti.rtf. Acesso em: 22 jul. 2020.

BICUDO, Maria Aparecida Viggiani. Ensino de Matemática e Educação Matemática: algumas considerações sobre seus significados. Bolema, Rio Claro, n. 13, p. 1-11, 1999. Disponível em:

https://www.periodicos.rc.biblioteca.unesp.br/index.php/bolema/article/view/10638. Acesso em: 15 jul. 2020.

BRITO, Marcia Regina Ferreira; PIROLA, Nelson Antonio. Aprendizagem Significativa e a formação de conceitos na escola. In: BRITO, Marcia Regina Ferreira de. Psicologia da Educação Matemática. Florianópolis, SC: Insular, 2005. p. 85-106.

CARVALHO, João Pitombeira de. Avaliação e perspectiva na área de ensino de Matemática no Brasil. Em Aberto, Brasília, n. 62, 1994. Disponível em:

http://rbep.inep.gov.br/ojs3/index.php/emaberto/article/view/2273/2012. Acesso em: 15 jul. 2020.

CANDAU, Vera Maria; ANDRADE, Marcelo; LUCINDA, Maria da Consolação; AMORIM, Viviane; PAULO, Iliane Aida; SACAVINO, Susana Beatriz. Educação em Direitos

Humanos e formação de professores (as). São Paulo: Cortez, 2013.

D'AMBROSIO, Ubiratan. Etnomatemática: elo entre as tradições e a modernidade. 2. ed. Belo Horizonte, MG: Autêntica, 2002.

D'AMBROSIO, Ubiratan. Etnomatemática, justiça social e sustentabilidade. Estudos Avançados, v. 32, n. 94, p. 189-204, set./dez. 2018. Disponível em:

https://www.scielo.br/scielo.php?script=sci_arttext\&pid=S0103-40142018000300189. Acesso em: 22 jul. 2020.

DESGAGNÉ, Serge. Réflexions sur le concept de collaborative. Les Jounées du CIRADE. Centre Interdisciplinaire de Recherche sur lÁpprentissage et lê Developpement em Éducation, Université du Québec à Montreal, octubre - 1998. pp. 31-46. Tradução-Livre: Adir Luiz Ferreira. Natal, 2003.

DISTRITO FEDERAL. Censo Escolar DF 2019. Secretaria de Estado de Educação do Distrito Federal: Brasília, DF. 2019. Disponível em: http://www.se.df.gov.br/censo-escolar2019. Acesso em: 15 jul. 2020.

ESTEBAN, Maria Teresa. O que sabe quem erra?: Reflexões sobre avaliação e fracasso escolar. Rio de Janeiro: DP\&A Editora, 2002. 
FERREIRA, Weberson Campos. Altas Habilidades/Superdotação Em Matemática e Inclusão: um estudo com professores no Distrito Federal. 2020. 157 f. Dissertação (Mestrado Profissional em Educação) - Universidade de Brasília - UnB, Brasília, 2020.

FRAZ, Joeanne Neves; HOTT, Daniela Francescutti Martins; MOREIRA, Geraldo Eustáquio; RODRIGUES, Georgete Medleg. Tecnologia Assistiva: Produtos e Serviços Disponíveis da Internet. PontoDeAcesso - Revista do Instituto de Ciência da Informação da UFBA, Salvador, v. 13, p. 70-84, 2019. Disponível em: https://portalseer.ufba.br/index.php/revistaici/article/view/35225/20736. Acesso em: 20 jul. 2020.

FREIRE, Paulo. À sombra desta mangueira. São Paulo: Olho d’Água. 1995.

GENTILI, Pablo. O direito à educação e as dinâmicas de exclusão na América Latina. Educação e Sociedade, Campinas, vol. 30, n. 109, p. 1059-1079, set./dez. 2009. Disponível em: http: https://www.scielo.br/pdf/es/v30n109/v30n109a07.pdf. Acesso em: 20 jul. 2020.

HYPOLITO, Álvaro Moreira. BNCC, Agenda Global e Formação Docente. Revista Retratos da Escola, Brasília, v. 13, n. 25, p. 187-201, jan./mai. 2019. Disponível em: http://retratosdaescola.emnuvens.com.br/rde/article/view/995/pdf. Acesso em: 15 jul. 2020.

KENSKI, Vani Moreira. Novas tecnologias - o redimensionamento do espaço e do tempo e os impactos no trabalho docente. Revista Brasileira de Educação, São Paulo, nº 8, pp. 58$71,1998$.

KNIJNIK, Gelsa. As novas modalidades de exclusão social - Trabalho, conhecimento e educação. Revista Brasileira de Educação, Rio de Janeiro, n. 4, p. 35-42, Jan./fev./mar./abr., 1997. Disponível em: http://www.anped.org.br/sites/default/files/rbe/files/rbe_04.pdf. Acesso em: 20 jul. 2020.

LÉSSART-HÉBERT, Michelle; GOYETTE, Gabriel; BOUTIN, Gérald. Investigação Qualitativa: Fundamentos e Práticas. Lisboa, Portugal: Instituto Piaget, 1994.

LIMA, Paulo Vinícius Pereira; MOREIRA, Geraldo Eustáquio; VIEIRA, Lygianne Batista; ORTIGÃO, Maria Isabel Ramalho. Brasil no Pisa (2003-2018): reflexões no campo da Matemática. TANGRAM - Revista de Educação Matemática, v. 3, 2020. p. 03-26.

MAGALHÃES, Maria Cecília Camargo; LIBERALI, Fernanda Coelho. A formação críticocolaborativa de educadores: a "vida que se vive" - uma complexa escolha metodológica. In: BALDI, Elena Mabel Brutten; PIRES, G. N. L.; FERREIRA, Maria Salonilde. Políticas educacionais e práticas educativas. Natal, RN: EDUFRN, 2011.

MANRIQUE, Ana Lúcia; MARANHÃO, Maria Cristina Souza de Alburquerque; MOREIRA, Geraldo Eustáquio. Desafios da Educação Matemática Inclusiva: Formação de Professores. Volume I. São Paulo: Editora Livraria da Física, 2016a.

MANRIQUE, Ana Lúcia; MARANHÃO, Maria Cristina Souza de Albuquerque; MOREIRA, Geraldo Eustáquio. Desafios da Educação Matemática Inclusiva: Práticas. Volume II. São Paulo: Editora Livraria da Física, 2016 b. 
MANTOAN, Maria Teresa Egler. Inclusão escolar: O que é? Por quê? Como fazer? SP: Summus, 2015.

MARTINHO, Maria Helena. Prefácio. In: MOREIRA, Geraldo Eustáquio (org.). Práticas de ensino de Matemática em cursos de licenciatura em Pedagogia: oficinas como instrumento de aprendizagem. São Paulo: Editora Livraria da Física, 2020. p. 7-9.

MOREIRA, Geraldo Eustáquio. Representações sociais de professoras e professores que ensinam Matemática sobre o fenômeno da deficiência. Tese (Doutorado em Educação Matemática) - Pontifícia Universidade Católica de São Paulo/Programa de Estudos PósGraduados em Educação Matemática, São Paulo, 2012.

MOREIRA, Geraldo Eustáquio; MANRIQUE, Ana Lúcia. Challenges in Inclusive Mathematics Education: Representations by Professionals Who Teach Mathematics to Students with Disabilities. Creative Education, n. 5, p. 470-483, 2014. Disponível em: https://www.scirp.org/journal/paperinformation.aspx?paperid=45390. Acesso em: 15 jul. 2020.

MOREIRA, Geraldo Eustáquio. A Educação Matemática Inclusiva no contexto da Pátria Educadora e do novo PNE: Reflexões no âmbito do GD7. Educação Matemática Pesquisa (Online), v. 17, p. 508-519, 2015. Disponível em: https://revistas.pucsp.br/index.php/emp/article/view/25667. Acesso em: 15 jul. 2020.

MOREIRA, Geraldo Eustáquio. O ensino de Matemática para alunos surdos: dentro e fora do texto em contexto. Educação Matemática Pesquisa, v. 18, p. 741-757, 2016. Disponível em: https://revistas.pucsp.br/index.php/emp/article/view/23486. Acesso em: 15 jul. 2020.

MOREIRA, Geraldo Eustáquio; SALLA, Helma. O Atendimento Pedagógico Domiciliar de alunos que não podem frequentar fisicamente a escola por motivos de saúde: Revisão Sistemática das investigações realizadas entre 2002 e 2015. Revista Educação Especial, vol. 31, n. 60, jan./abr., 2018. Disponível em:

https://periodicos.ufsm.br/educacaoespecial/article/view/26680. Acesso em: 15 jul. 2020.

MOREIRA, Geraldo Eustáquio. Tendências em Educação Matemática com enfoque na atualidade. In: NEVES, Regina da Silva Pina; DÖRR, Raquel Carneiro (orgs.). Formação de Professores de Matemática: Desafios e perspectivas. 1. ed. Curitiba, PR: Appris, 2019. p. 45-64.

MOREIRA, Geraldo Eustáquio; MANRIQUE, Ana Lúcia. Educação Matemática Inclusiva: Diálogos com as Teorias da Atividade, da Aprendizagem Significativa e das Situações Didáticas. 1. ed. São Paulo - SP: Livraria da Física - LF, 2019.

MOREIRA, Geraldo Eustáquio (org.). Práticas de Ensino de Matemática em Cursos de Licenciatura em Pedagogia: Oficinas como instrumentos de aprendizagem. São Paulo: Editora Livraria da Física, 2020a.

MOREIRA, Geraldo Eustáquio. O Dzeta Investigações em Educação Matemática numa perspectiva de resistência e persistência. In: MOREIRA, Geraldo Eustáquio (org.). Práticas de Ensino de Matemática em Cursos de Licenciatura em Pedagogia: Oficinas como instrumentos de aprendizagem. São Paulo: Editora Livraria da Física, 2020 b. 
ORTIGÃO, Maria Isabel Ramalho (org). Políticas de avaliação, currículo e qualidade: diálogos sobre o PISA. 1. ed., Curitiba, PR: CRV, 2018.

PADILHA, Paulo Roberto. Educação em Direitos Humanos sob a ótica dos ensinamentos de Paulo Freire. In: SCHILLING, Flávia (org.). Direitos humanos e educação: outras palavras, outras práticas. São Paulo: Cortez, 2005. p. 166-176.

PAIS, Luiz Carlos. Ensinar e aprender Matemática. Belo Horizonte, MG: Autêntica, 2006.

PAIVA, Thiago Ferreira de. Recursos didáticos e as mediações necessárias para uma aprendizagem significativa para estudantes com NEE em aulas de Matemática. 2019. 146 f. Dissertação (Mestrado em Educação) - Universidade de Brasília, Brasília, 2019.

PERRENOUD, Philippe. Construir as competências desde a escola. Trad. Bruno Charles Magne. Porto Alegre, RS: Artmed Editora, 1999.

SAVIANI, Demerval. Trabalho e educação: fundamentos ontológicos e históricos. Revista Brasileira de Educação, v. 12, n. 34, 2007. Disponível em: https://www.scielo.br/pdf/rbedu/v12n34/a12v1234.pdf. Acesso em: 20 jul. 2020.

SOUZA, Meire Nadja Meira de. Avaliação formativa em Matemática no contexto de jogos: a interação entre pares, a autorregulação das aprendizagens e a construção de conceitos. 2019.196 f. Dissertação (Mestrado em Educação) - Universidade de Brasília, Brasília, 2019.

TEIXEIRA, Cristina de Jesus; MOREIRA, Geraldo Eustáquio. A proposição de problemas como estratégia de aprendizagem da Matemática: Uma ênfase sobre efetividade, colaboração e criatividade. São Paulo: Editora Livraria da Física, 2020.

TEIXEIRA, Cristina de Jesus; PAIVA, Thiago Ferreira; MOREIRA, Geraldo Eustáquio. Matemática e Inclusão: para além dos resultados. Revista da Sociedade Brasileira de Educação Matemática, São Paulo, v. 15, n. 20, p. 389-408, set./dez. 2018. Disponível em: https://www.revistasbemsp.com.br/index.php/REMat-SP/article/view/170. Acesso em: $20 \mathrm{jul}$. 2020 .

VIEIRA, Lygianne Bastista; MOREIRA, Geraldo Eustáquio. Direitos Humanos e Educação: O professor de Matemática como agente sociocultural e político. Revista de Educação Matemática, São Paulo, v. 15, p. 548-564, 2018. Disponível em: https://www.revistasbemsp.com.br/REMat-SP/article/view/174/pdf. Acesso em: 15 jul. 2020.

VIEIRA, Lygianne Batista; MOREIRA, Geraldo Eustáquio. Sociedade Contemporânea e o Ensino de Matemática: Conexões com a Educação em Direitos Humanos. Brazilian Applied Science Review (BASR), v. 04, 2020a. p. 478-490. Disponível em:

https://www.brazilianjournals.com/index.php/BASR/article/view/7872/7426. Acesso em: 20 jul. 2020.

VIEIRA, Lygianne Batista; MOREIRA, Geraldo Eustáquio. Políticas Públicas no âmbito da Educação em Direitos Humanos: conexões com a Educação Matemática. Revista REAMEC, Cuiabá (MT), v. 8, n. 2, maio-agosto, 2020b. p. 622-647. Disponível em: 
http://periodicoscientificos.ufmt.br/ojs/index.php/reamec/article/view/10500/pdf. Acesso em: 20 jul. 2020.

VIEIRA, Lygianne Batista; MOREIRA, Geraldo Eustáquio. O estudante imigrante e o papel do professor de matemática como agente sociocultural e político. Dialogia, São Paulo, v. 01, 2020c. p. 185-199. Disponível:

https://periodicos.uninove.br/index.php?journal=dialogia\&page=article \&op=view\&path $\% 5 \mathrm{~B}$ $\% 5 \mathrm{D}=16711 \&$ path\%5B \%5D=8230. Acesso em: 22 jul. 2020.

VIGOTSKY, Lev Semenovich. A construção do pensamento da linguagem. São Paulo: Martins Fontes, 2001.

VILA, Antonio; CALLEJO, Maria Luz. Matemática para aprender a pensar: o papel das crenças na resolução de problemas. Porto Alegre, RS: Artmed, 2006.

\section{Agradecimentos}

Resta-nos, por oportuno, agradecer aos envolvidos nesta pesquisa (formadores; estudantes da graduação da UnB; professores e gestores das escolas públicas; estudantes da Educação Básica e oficineiros), com distinção aos membros do Grupo de Pesquisa, nomeadamente Dzeta Investigações em Educação Matemática (DIEM); à Secretaria de Estado de Educação do Distrito Federal (SEEDF); à Fundação de Apoio à Pesquisa do Distrito Federal (FAPDF); à Faculdade de Educação da Universidade de Brasília (FE/UnB); ao Instituto Nacional de Estudos e Pesquisas Educacionais Anísio Teixeira (INEP); ao Conselho Nacional de Desenvolvimento Científico e Tecnológico (CNPq); à Coordenação de Aperfeiçoamento de Pessoal de Nível Superior (Capes, Códigos de Financiamento 001 e PNPD/Capes: 88887.463536/2019-00, 2020); aos Programas de Pós-Graduação em Educação da Universidade de Brasília (PPGE/UnB - Acadêmico e Profissional); ao DPI/UnB e ao DEX/UnB e, ainda, aos Projetos de Pesquisa "Formação do Professor de Matemática na Perspectiva da Educação do Campo: formação e prática docente, didáticas específicas de Matemática e acompanhamento da aprendizagem do aluno" (UnB e FAP/DF) e "Do ensino presencial ao ensino remoto emergencial em função da Covid-19: Apoios educacionais, sociais e tecnológicos para professores da rede pública de ensino do Distrito Federal” (UnB/DPI/DEX). 